\title{
"My mind is not like before": Psychosocial rehabilitation of victims of torture in Athens
}

\author{
Gail Womersley, *, Laure Kloetzer, *, Rafael Van den Bergh,**, Emilie \\ Venables, **, ***, Nathalie Severy, **, Nikos Gkionakis,****, Christina \\ Popontopoulou, $* * * * *$, Manolis Kokkiniotis, *****, Federica Zamatto, **
}

Key points of interest:

- Torture and forced migration represent two significant interrelated sources of trauma.

- This study highlights the significant impact of the political, legal, and sociocultural environment on processes of psychosocial rehabilitation.

\footnotetext{
Abstract

Introduction: The dual trauma of being a victim of torture as well as a refugee is related to a myriad of losses, human rights violations and other dimensions of suffering linked to torture experienced pre-migration, as well as different forms of violence

* Institute of Psychology and Education, University of Neuchatel, Switzerland

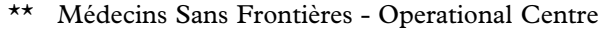
Brussels

$\star \star \star$ Division of Social and Behavioural Sciences, School of Public Health and Family Medicine, University of Cape Town, South Africa

$\star \star \star \star$ Babel Mental Health Day Care Centre, Athens, Greece

$\star \star \star \star \star$ Médecins Sans Frontières - Operational Centre Brussels, Centre for Victims of Torture and ill-treatment, Athens, Greece

Correspondence to: gail.womersley@unine.ch
}

experienced during and after migration. Method: To present three case studies to explore culturally-informed perspectives on trauma among victims of torture and track trajectories of psychosocial rehabilitation in relation to environmental factors. The case studies are part of a larger qualitative study of asylum seekers and refugees in a center for victims of torture in Athens, managed by Médecins Sans Frontières and Babel in collaboration with Greek Council for Refugees, which follows beneficiaries, their care providers and community representatives and leaders. Results: Key themes emerging include the substantial psychological impact of current material realities of migrant victims of torture as they adapt to their new environment and engage in rehabilitation. Delayed asylum trials, poor living conditions and unemployment have a substantial impact on posttraumatic symptoms that in turn influence psychosocial rehabilitation. Personal, social, and cultural resources emerged as having a mediating effect. Discussion: The results highlight the significant impact of the political, legal, and sociocultural environment on psychosocial rehabilitation. Practical implications for interventions are to ensure 
holistic, interdisciplinary, and culturally sensitive care which includes a focus on environmental factors affecting resilience; and with a dynamic focus on the totality of the individual over isolated pathologies.

Keywords: Torture, rehabilitation, environmental impact, trauma, posttraumatic stress disorder

\section{Introduction}

The mental health impact of atrocities endured by refugees ${ }^{1}$ is clear, with a high prevalence of post-traumatic stress disorder (PTSD) reported among this population. Torture has emerged as a particular triggering factor (Haenel, 2015; Hodges-Wu \& Zajicek-Farber, 2017; Silove, Ventevogel, \& Rees, 2017; Song, Subica, Kaplan, Tol, \& de Jong, 2017). This is no surprise, given the multiplicity of challenges to which refugee Victims of Torture (VoTs) are exposed. The dual trauma inherent in being both a VoT as well as a refugee is related to a myriad of losses, human rights violations and other dimensions of suffering linked not only to torture experienced premigration, but trauma experienced during and post-migration as well (Hodges-Wu \& Zajicek-Farber, 2017). Trauma does not stop at the border.

Torture itself represents an extraordinary exception in the psychopathology field. The act itself is taught, organised, elaborated, and perpetrated by humans against other humans, disrupting our connections to all that make us human (Sironi, 1999; Viñar, 2005). It is not an individual act, but a social and

1 Here, we use the term "refugee" as defined by the Geneva Convention of 1951 to include both refugees legally recognised in a host country as well as asylum-seekers. political one. These far-reaching effects may interact and manifest in complex and diverse ways, mediated by culture, gender and other aspects of the context of the torture survivor, the context of torture and the context of the recovery environment (Patel, Kellezi, \& Williams, 2014). Furthermore, environmental stressors associated with exile, resettlement, and acculturation continue to further threaten individual health and well-being among refugee VoTs. Post-migration factors are a fundamental consideration in light of the additional critical life events which refugees face, and which have clearly emerged in the literature as exacerbating posttraumatic reactions (Hollander et al., 2016; Schock, Böttche, Rosner, Wenk-Ansohn, \& Knaevelsrud, 2016; Song, Kaplan, Tol, Subica, \& de Jong, 2015; ter Heide, Mooren, \& Kleber, 2016). Yet, despite this growing body of critical literature, there has been relatively little research regarding how current environmental factors and resettlement variables affect the psychosocial rehabilitation of VoTs (Hodges-Wu \& Zajicek-Farber, 2017; Whitsett \& Sherman, 2017).

It must be noted that criticism has been levelled against the use of PTSD as a diagnosis within this context. NavarroLashayas and colleagues (2016) highlight the risk of medicalising a socio-political problem and individualising social suffering. This oversimplification of the complexity of human suffering serves to depersonalise and victimise the individual (Kotsioni, 2016). Torture is not a disease. In terms of clinical approaches, Papadopoulos (2007) underlines that psychological reactions to adversity vary enormously from individual to individual. His framework suggests that even psychological phenomena such as a posttraumatic response do not occur in social isolation; the wider community and cultural contexts matter a great deal as they are 
active in forming at least part of the meaning systems, and consequently the rehabilitation, of each individual.

These theoretical frameworks take into account the fact that humans are essentially social beings, and that, equally, symptom severity is not static but fluid and changing due to a wide range of interacting intrapsychic and external factors. There is thus a need to explore trauma 'in context'notably through exploring processes of psychosocial rehabilitation of victims of torture within the specific historical, cultural, social, and political context of the "reception crisis" in Europe. This is important not only in order to challenge the concept of PTSD, but also to provide more appropriate mental health care to VoTs with a consideration for both cultural factors as well as the impact of current environmental stressors on the process of rehabilitation. Therefore, in order to i) explore culturally-informed perspectives on trauma among VoTs from an individual, qualitative perspective and ii) track trajectories of psychosocial rehabilitation in relation to environmental factors, we present a case series from the results of 12 months of research among asylum seekers and refugees in a center for victims of torture in Athens, managed by Médecins Sans Frontières (MSF) and Babel (a mental health unit for migrants and refugees operating in Athens since 2007) in collaboration with the Greek Council for Refugees (GCR).

\section{Methodology}

The study design involved in-depth interviews with three VoTs and their care providers over the course of a year.

\section{Study setting}

Victims of torture in Athens, Greece: As the "reception crisis" continues unabated, Greece remains one of the first ports of sanctuary. While the country is still gripped by one of the worst financial and societal crises of the past 40 years, little attention or funding is available to provide mental health and psychosocial support to refugees (Gkionakis, 2016). According to recent statistics provided for March 2018 by the $\mathrm{UNHCR},{ }^{2}$ over 50,000 asylum seekers and refugees currently remain in Greece, following the 2015-2016 mass flow. This population is legally entitled to free access to medical care, yet the ability of the Greek health system to provide adequate health care to refugees upon entry is severely stretched as a result of the ongoing economic crisis, resulting in numerous barriers to access (MDM, 2016). These challenges are even more pronounced for migrants faced with a lack of information and linguistic and cultural barriers to accessing an unfamiliar system. Often living in harsh and isolating conditions, a 2017 report by $\mathrm{UNHCR}^{3}$ estimates that many migrants will wait for over two years to find out about their asylum status.

There are few reliable statistics concerning the number of VoTs currently in Greece (European Union Agency for Fundamental Rights, 2017; MSF, 2016; UNHCR, 2017). The UNHCR has estimated that among refugee populations, between 5 and 35 percent are torture survivors, yet highlights that the actions that are needed to identify and support and enable them to claim their rights are too often ignored or purposely excluded (UNHCR, 2017). In Greece, few rehabilitation or identification services are

2 https://reliefweb.int/sites/reliefweb.int/files/resources/62950.pdf

3 http:/www.unhcr.org/publications/ operations/58d8e8e64/unhcr-recommendationsgreece-2017.html 
provided to survivors of torture by a state structure or sustainably by NGOs apart from one organisation, Metadrasi, who certified 650 VoTs from 2017-2018. ${ }^{4}$ Most efforts of identification appear to be ad-hoc or dependent on some form of self-identification. This complex asylum system, the poor identification of VoTs and the many barriers in accessing basic services in Athens and across the country have had a substantial, adverse impact on mental health (Kotsioni, 2016). It has also lead to health professionals under pressure "medicalising" the psychological suffering (for example, through the use of a certified PTSD diagnosis) as part of the identification process (FRA, 2017), as has been noted elsewhere in Europe (d'Halluin, 2016; Fassin \& d'Halluin, 2005).

MSF and Babel clinic for rehabilitation of victims of torture and other forms of ill-treatment: In April 2013, the GCR jointly with Babel Day Centre and Dignity (the Danish Institute Against Torture) started the implementation of the Prometheus project, funded by the EU. Prometheus project's main goal was to deliver identification and rehabilitation to VoTs through health and mental health service provision, as well as legal and social support. In September 2014, MSF joined this partnership. Since 2014, MSF, Babel and GCR have established a unit delivering medical care, legal support, mental health care and social support to VoTs, training and supervision to the staff of this unit and training and consultation to other actors who work with VoTs. The unit adopts the IFRC definition of torture and ill-treatment (where torture is defined as consisting of severe pain or suffering, whether physical or mental,

4 http://metadrasi.org/en/campaigns/certificationof-torture-victims/ inflicted for such purposes as obtaining information or a confession, exerting pressure, intimidation or humiliation) and operates as an interdisciplinary team applying a holistic approach to the rehabilitation of torture survivors.

\section{Study population}

This case series is a part of a larger qualitative study conducted by the first author over the period of a year in the MSF clinic in collaboration with Babel, with supervision and assistance by the other authors. Ten individual VoTs, collectively identified by the health professional team were followed over this period, with an average of five indepth interviews being conducted with each participant. All ten had been beneficiaries of the clinic for over six months and had found accommodation in Athens, not in the refugee camps. For this case series, three VoT participants out of the ten were selected as representative cases to explore the impact of the environmental, legal, and cultural context on psychosocial rehabilitation of torture.

\section{Ethics}

All study participants were informed of the purpose of the research, and provided written consent for the interviews to be taken and their information to be used. Consent was given for care providers to be interviewed by the individual beneficiaries of the project. The study was approved by the ethics committee of the University of Neuchatel, the Ethics Review Board of MSF and the scientific review committee of Babel.

\section{Results}

Key themes emerging across interviews with the three selected participants included the substantial psychological impact of current material realities of migrant VoTs as they adapt to their new environment 
and engage in a process of psychosocial rehabilitation. The periods before and after being granted asylum were identified as two distinct phases in the psychological lives of these individuals, each with specific stressors. Delayed asylum trials, poor living conditions and unemployment emerged as having a substantial impact on posttraumatic symptoms that in turn influenced psychosocial rehabilitation. Personal, social, and cultural resources similarly emerged as having a mediating effect on the stressors identified above.

The first case presented, that of $\mathrm{D}$, focuses on the influence of environmental context (including, for example, current political, material and economic conditions). The second case, that of $\mathrm{J}$, focuses on the legal context and the third case, that of $\mathrm{B}$, focuses on the cultural context.

\section{The case of $D$}

$\mathrm{D}$ is a 30-year-old asylum seeker and VoT. In 2007, he was arrested and tortured on numerous occasions in his country of origin, often for months at a time, due to his involvement as a political activist. $\mathrm{He}$ managed to escape from prison with the help of an uncle, and arrived, alone, in Athens to seek asylum where he was referred to the MSF/Babel centre.

Over the course of the four interviews, he described the various methods of torture to which he was subjected, in minute detail, including sexual abuse, his legs being "ripped apart", the meta-tarsals in his feet being broken, as well as electrification: "They give me the scars on my soul...lots of things from my mind has been wasted."

For the first four months after his arrival, he was living alone in a 30 meter-squared hotel room in an old building recently remodelled to house asylum seekers. During this time, he explained:

"I don't have any friends here, I don't have any relatives, I don't have any family members, I don't even know any [religion removed] community here. I know that there are a lot of [religion removed] people living here, my new community is here, not 'my'

Figure 1: Timeline of the key elements in the pre-migration and post-migration life of $D$, emphasising the influence of environmental context.

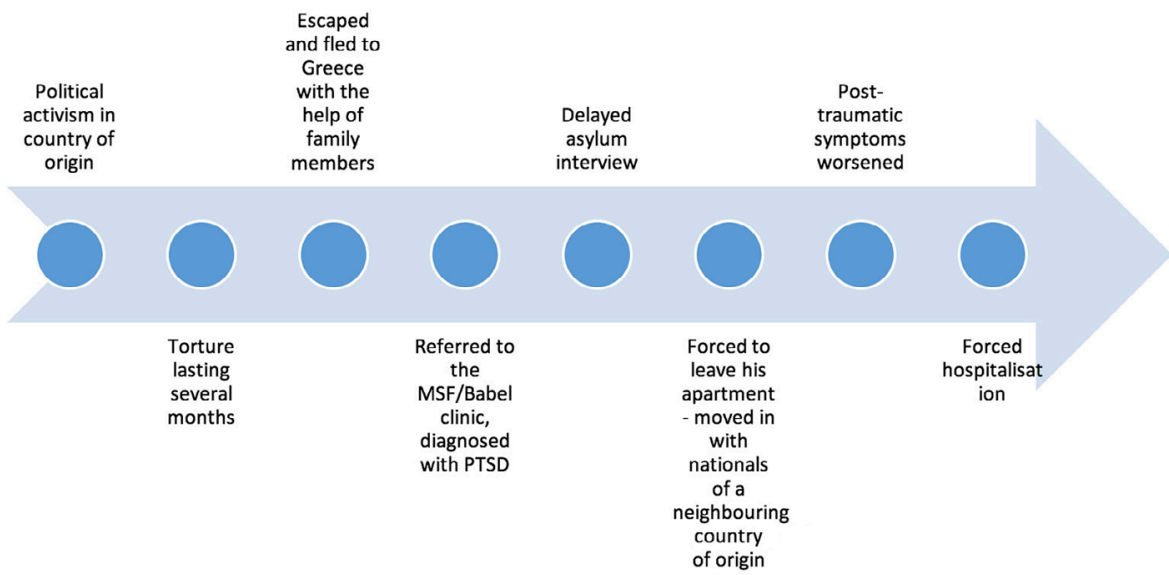


community... when I am staying at a hotel, whenever somebody is knocking at the door,

I feel scared... I never go out"

The physical, social, and cultural isolation served merely to exacerbate his post-traumatic symptoms: a vicious cycle of feeling scared and alone, alone and scared. Furthermore, the disconnection cannot be considered as a "one-off" event, which occurred at a particular moment: disruptions continued with each phone call bringing news from his home country and every day spent alone in a hotel room. $\mathrm{D}$ was given an appointment for his asylum interview. However, the administrator responsible was not present on the day and the procedure was delayed. This contributed to further disconnections in visibility, representation and the acknowledgement of the torture which he had endured. The uncertainty, and sense of being "stuck" also appeared to have impeded his process of psychosocial rehabilitation:

"I know only one thing, that my world is just only this room... I'm just killing my time here until I'm not getting my papers or they are not going to take my interview"

Due to financial reasons, he was forced to move out of his small hotel room into shared accommodation. He accused his roommate of spying on him, a roommate who incidentally came from a neighbouring country that D suspected of having political ties with his own. Psychotic symptoms started to emerge, including auditory hallucinations and symptoms of paranoia. Many of the voices were those of authority figures, including the torturers in his country of origin and, tellingly, police officers, bureaucrats and judges in the asylum procedure in Greece. He reported experiencing auditory hallucinations, with voices claiming that he was going to be homeless. The voices also told him that "they" would not believe him, that "they" would send him back to his home country. Given his current living conditions in Athens, these fears were not without reasonable grounds.

He was hospitalised as a result of these hallucinations in a psychiatric ward of a general hospital. He perceived this repeated institutionalisation as a further enforced period of detention where he was subjected to bodily treatments against his will. It appeared to have triggered memories of the past torture he endured. He described the hospital as having a prison-like atmosphere. The hospital staff promised that they would not give him injections, which they subsequently did. This deepened his sense of mistrust, paranoia and isolation-further exacerbating symptoms. Furthermore, during this period he received news that his mother was in prison, and suffering from severe medical complications. There was no clear news about his father. With each phone call from his country of origin, psychotic symptoms worsened.

One caregiver noted the impact of his current reality on the process of diagnosis:

"I could see the face of the psychiatrist who at first said, 'You think the secret services of [country removed] are after you?' I could see the paranoia. Then he said his story. There he goes, "Oh, oh, oh, oh." [laughter] This is not paranoia. This is real life."

The phrase "this is real life" is indeed telling: D's "real life" — characterised by poor living conditions, social isolation, and delayed asylum trials, played a key role in his mental health. His case highlights the role of "feedback loops" (Kirmayer \& Ramstead, 2017)—vicious cycles wherein symptoms were exacerbated by "real life" events and which played a key role in his psychosocial rehabilitation. 
The case of $\mathcal{F}$

$\mathrm{J}$ is a 45-year-old African man, unmarried and the father of one nine-year-old son. $\mathrm{He}$ was arrested and tortured after engaging in anti-government protests. After arriving in Athens in December 2015, he was referred to $\mathrm{MSF} / \mathrm{Babel}$ for serious medical complications as a result of the torture he suffered, and was seen by a doctor, physiotherapist, lawyer, social worker and psychologist.

When first interviewed, $\mathrm{J}$ described his situation as the following:

"We are human beings, but I am an adult without a wife, without a child. My life is bloody ruined, everyone is in the same hole, who can change it? Nobody. Nobody cares about us... [these problems] devour us. If I was well, you could see that I was well, but I'm sick, I'm not in good health. I'm physically fine, but in my interiorI'm not at all okay [...] I'm with the others but not in spirit"5

5 Loose translation from the original interview conducted in French.
His mental health, did, however start to improve with a multi-disciplinary intervention. A few weeks later, he confirmed that:

"I was traumatised before, I had too much fear, but the social worker did everything to calm me [...] the psychologist is also a person that you can tell everything to: social, emotional, everything..."

During his first asylum interview, he had to speak about the torture he endured, an event that he described as having "retraumatised" him:

"It's a story that hurts you and causes a lot of emotions [...] the pain that I felt that day, that could be at $10 \%$, if the pain has passed, but if you have to repeat the story, you feel it at 100\% [...] it hurts you to have to tell your story, yes it hurts. Even during the interview, it hurts you."

Despite his testimony, and having medical certification attesting to the physical injuries resulting from the torture, his request for asylum was denied. J, however, refused to accept this:

"I refused. I said " no, this can't be happening, I have all the proof to show...I

Figure 2: Timeline of the key elements in the pre-migration and post-migration life of $\mathcal{F}$, emphasising the influence of the legal context.

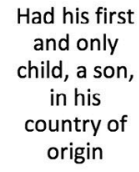

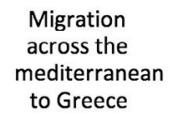

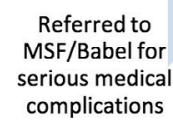


can talk, I can lie, but the proof doesn't lie, the echocardiogram proves everything." I was really affected. I had a fever [...] yes I was emotional, I was alone with the interpreter and the three judges and the lawyer. It's tough. Man, man has no pity for man, no pity. Oh it's tough! To be a migrant is tough, to re-enter into a normal life is tough [...] during the asylum interview, my head heated up. All of the calculations that I'd had, none of them worked out. I thought that, with this news, they won't give me a house, it's difficult to eat, in these really bizarre conditions."

As was the case for $\mathrm{D}$, the fact that his story was not believed appeared to have the most significant impact on him. Furthermore, he equated being an asylum seeker as living in "bizarre conditions" of permanent temporariness. He described feeling mocked, teased, humiliated and ill-treated by bureaucrats throughout the asylum process. Despite his request for asylum being denied, $\mathrm{Mr} \mathrm{J}$ requested an appeal and continued his process of psychosocial rehabilitation. When interviewed after submitting the appeal, he stated that:

"There have been some big changes because when you cry a lot, there's a moment where you stop crying. You see the reality in front of you. I have already suffered a lot from thinking, thinking. I must think until where and until when? Must I spend my whole life crying? [...] Since being here, the pain has changed [...] The essential is that I'm in good health. I'm alive. It's not the end of the world. Life continues."

He suggested that his improvement in mental health was related to a variety of factors: the resilient spirit that his father had instilled in him as a young boy, the assistance of a community in Athens from his country of origin, the holistic and multidisciplinary approach of his psychosocial rehabilitation and, simply, time. His case exemplifies the impact of the legal context on mental health. It highlights the necessity of a multi-disciplinary approach to psychosocial rehabilitation, including a team of social workers, lawyers, psychologists, doctors, cultural mediators, and psychiatrists. If one element of these is lacking, it may slow down or inhibit the activities of the others.

\section{The case of $B$}

$B$ is a 35-year-old African woman, mother of four children and a victim of torture and of forced circumcision. Upon arriving in Greece, she presented frequently to the emergency services with multiple physical complaints, which were diagnosed as psychosomatic. She was similarly diagnosed with PTSD and referred to MSF/Babel for mental health care.

When asked about her experience of trauma during our first interview, B explained that:

"I have a fear of everything, a fear of life, in fact, because me, I always say, "if you don't take decisions, I wouldn't have left my country" and that fear of 'that practice' [of torture] also evoked fear in me. I left my children behind me-what will happen to them? How are they over there? How do they live? How are they eating? How are they sleeping? This fear has developed in me and it's tiring. I even told my psychologist that I have this fear that I don't know how to explain, this fear that I want to leave me..."

She related her experience of fear to both the isolated incident of torture she endured, as well as to multiple other factors, including having been forced to leave her children, as well as her uncertain future. She felt unable to return to her country, but also unable to engage in a process of rehabilitation for 
Figure 3: Timeline of the key elements in the pre-migration and post-migration life of $B$, emphasising the influence of the cultural context.

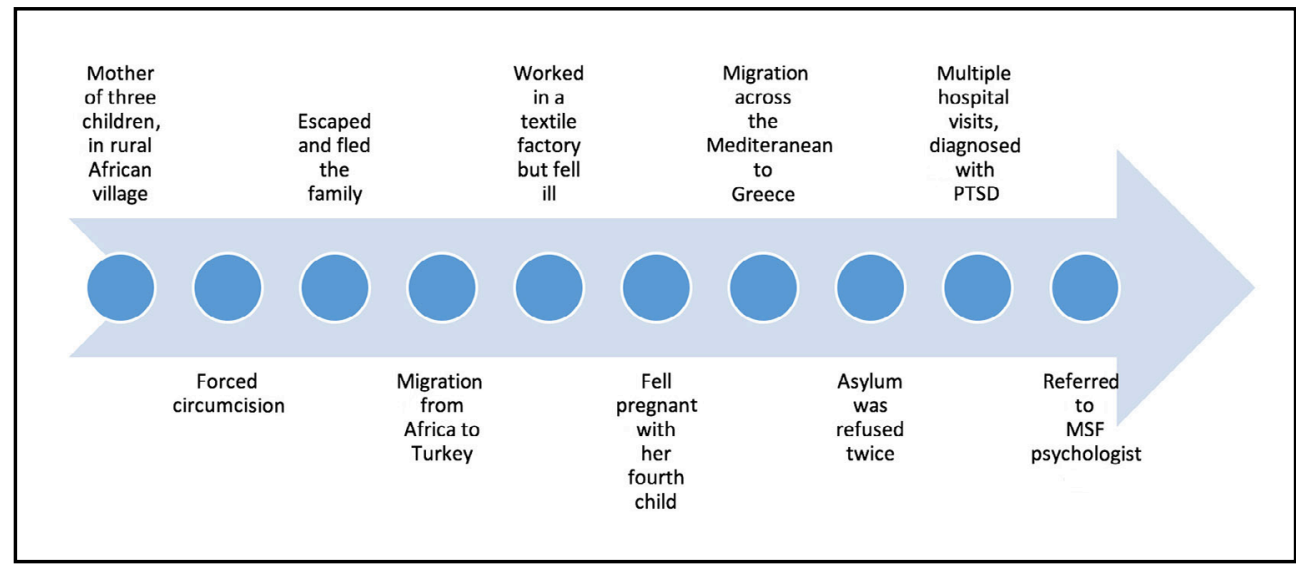

the future. No one single incident could account for this unexplainable fear. Thus paralyzed, she remained isolated from others, barely leaving her apartment except for the occasional visit to the clinic to see her psychologist.

A few months later, she explained:

"The psychologist told me that the nightmares are linked to the past, because I told him that I'm being chased. He told me that it's linked to the past, that's it." I told him that it's spiritual, but afterwards, when he spoke, I told myself that "I don't know" but it's also possible that it's linked to what I'm thinking in my head. It's also that. Because I leave what's in my head. If I remove what's in my head, it can sort itself out. Apparently, when you have dreams where people are chasing you, we, we say that it's witchcraft. Among the Africans, we say that it's witchcraft. But he, he explained to me that ... for example, I had a dream the night before last. I remember two dreams. Where they chained me up, he said that it's linked to my past and that it's me myself who is chaining myself up.
B was confronted with two varying, and culturally informed, ways of understanding her post-traumatic symptomatology. For her, the nightmares she experienced may be explained "spiritually" - in other words, based on the spiritual and cultural belief systems of her home community. Within this belief system, the nightmares are not perceived to be directly linked to the torture she experienced, but to witchcraft: the family has cursed her for leaving. She appeared to examine these two possible explanations. Her words, "I don't know but it's also possible" reflected her ambivalence towards the meaning behind the nightmares:

"Because maybe, in my head, I am guilty, it's true....but Christ has already forgiven me. That's also the problem [...] spiritually, it's complex. What I see, I explain spiritually with the hand of witchcraft. It means that the family isn't leaving me in peace. Spiritually, they are following me, they followed me two nights ago until I was scared. I don't know, there are two explanations. Apparently there is an explanation that's different to what I think myself. So I don't know which to leave or 
take. I don't know...but I told myself that maybe that one's right as well."

The spiritual resources she drew on to understand the meaning of the nightmares are linked not only to African traditional spirituality involved in witchcraft, but to Christian beliefs. She herself highlighted the complexity of this. On a symbolic level, the fact that she believed Christ to have forgiven her appears to have had a significant impact on her levels of guilt and other associated forms of emotional distress. She further explained that apart from going to see her psychologist, the other person to whom she was able to share her experiences of trauma was her priest.

A few months later, she described a dramatic decrease in her symptomsboth physical and psychological. There was similarly an increase in her social connections to others:

"I was speaking with the psychologist. Speaking really helped me a lot. I don't have nightmares any more. Because of speaking with him, because of his advice, I would say that things are going all right. And there are many changes, because of speaking with him, I smile, I'm not too stressed like before. There are many changes that I see in myself."

What's interesting to note is the key involvement of social relations in her rehabilitation process. The decrease in symptoms was attributed to "speaking" which "really helped me a lot." Another integral part of her rehabilitation has been the connection to others. Being able to speak not only to the psychologist, but to her roommates, was part of the process of rehabilitation as well as a potential indicator of its success-she framed the social connection as both something which helped her to forget, as well as an indicator of change in herself. As such, the social connections possibly reflect both the cause and consequence of the improvement in her mental health; a positive feedback loop wherein connection to others decreases the post-traumatic symptoms and this decrease in symptoms allows for an increase in ability to connect socially.

\section{Discussion}

The cases above attest to the significant impact of the environmental, legal, and sociocultural context on processes of psychosocial rehabilitation among refugee VoTs. This includes the broader socioeconomic framework in host countries and the ways in which these frameworks may hinder or facilitate rehabilitation. Daily stressors represent proximal, ongoing and often chronic threats to psychological wellbeing. Due to this chronicity, these daily stressors may gradually erode coping resources and tax mental health-creating conditions for feelings of powerless and helplessness linked to a real or perceived loss of control over the environment (Miller \& Rasmussen, 2017). This echoes the plethora of research already conducted on mental health of refugees indicating the adverse effects of post-migration stressors (Chen, Hall, Ling, \& Renzaho, 2017). As for many other VoTs across the world, the process of seeking asylum itself was a seemingly retraumatising experience for the participants on many levels. Firstly, it could be argued that the perception of illtreatment at the hands of an indifferent yet powerful state apparatus may be reminiscent of the torture conditions to which they were subjected in their country of origin. Secondly, the very experience itself of having to recount the horror of the experience of torture in an asylum tribunal may be equally traumatising (Schock, Rosner, \& Knaevelsrud, 2015). 
All three people in the cases highlighted above were diagnosed with PTSD, yet the diagnosis did not appear to be particularly relevant to their lives, or the way in which they made sense of their psychological suffering. None referred to the diagnosis spontaneously during the multiple interviews conducted over a 12 month period. Their main concerns appeared to be focused on the present conditions in which they found themselves, characterised by numerous environmental stressors and an uncertain future. There did not seem to be anything "post" about the "P" of PTSD. This echoes the conclusions of Patel and colleagues (2014) that "problems of torture survivors need to be defined far more broadly than by PTSD symptoms, and recognition given to the contextual influences of being a torture survivor, including as an asylum seeker or refugee, on psychological and social health" (p. 2). In contrast to the seeming irrelevance of the formal diagnosis of PTSD, the relationship with the multidisciplinary team was noted by all of the participants as being an integral part of their rehabilitation. What appears to have had the most impact was being seen as an individual human being, and being treated with dignity.

\section{Conclusion}

The research findings highlight the need for psychosocial interventions to incorporate a more contextualised understanding of trauma as being largely determined by larger cultural systems and socio-political contexts. It also highlights the importance of seeing the strengths and resilience of most refugees and their potential contributions to host societies (Bäärnhielm, 2016). Psychosocial rehabilitation of torture survivors, particularly refugees, needs to reflect this complex reality. Focus should be placed on the practical realities of the post- migration environment, interdisciplinary approaches to care and quality cultural mediation. Interventions should become the mirror in which the individual will be able to relink the shattered pieces of him/herself into a totality. This requires a strong team of experienced professionals, teamwork of an inter-disciplinary nature, and stability at an organisational level (Kotsioni, 2016) for an integrated system of care for VoTs which provides a coordinated, compassionate, and comprehensive support (Kira, 2010). For the above aim to be achieved, it is important that the interventions planned and implemented take into consideration the environmental factors and the broader socio-economic and political system of the reception countries. The needs of this population are varied and complex, necessarily demanding a multidisciplinary approach to intervention which may be beyond the current capacity of the national health service at present.

VoTs may experience a disconnection from their body, their emotions and their identity and need to regain trust in other human beings, society and themselves. This is a complex process in which professionals need to be able to acknowledge the individual not as a patient, but a totality. It is vital that the professionals do not limit themselves to a diagnosis and treatment of symptoms but rather focus on how to empower the individual to regain control. Conceptualising the mental health of refugees requires the recognition of the role of both pre-migration trauma and post-migration stressors and that psychological distress can manifest in various ways. As stated by Viñar (2005), we cannot listen to a tortured man and see an understanding of his person unless we dare to take a little interest in the oppressive order that destroyed him; not only to seal his wounds, but also to restore his humanity. 


\section{References}

Bäärnhielm, S. (2016). Refugees' mental health-a call for a public health approach with focus on resilience and cultural sensitivity. European Fournal of Public Health, 26(3), 375-376. https:// doi.org/10.1093/eurpub/ckw055

Chen, W., Hall, B. J., Ling, L., \& Renzaho, A. M. (2017). Pre-migration and post-migration factors associated with mental health in humanitarian migrants in Australia and the moderation effect of post-migration stressors: findings from the first wave data of the BNLA cohort study. The Lancet Psychiatry, 4(3), 218-229. http://dx.doi.org/10.1016/ S22150366(17)30032-9

d'Halluin, E. (2016). Le nouveau paradigme des «populations vulnérables» dans les politiques européennes d'asile [The new paradigm of «vulnerable populations" in the European politics of asylum.] Savoir/Agir, 36(2), 21-26. https://doi. org/10.3917/sava.036.0021

Fassin, D., \& d'Halluin, E. (2005). The truth from the body: medical certificates as ultimate evidence for asylum seekers. American Anthropologist, 107(4), 597-608. https://doi.org/10.1525/ aa.2005.107.4.597

FRA [European Union Agency for Fundamental Rights]. (2017). Current migration situation in the EU: Torture, trauma and its possible impact on drug use. Luxembourg: Publications Office. http:// dx.doi: $10.2811 / 82527$

Gkionakis, N. (2016). The refugee crisis in Greece: training border security, police, volunteers and aid workers in psychological first aid. Intervention, 14(1), 73-79.

Haenel F. (2015) Special Problems in the Assessment of Psychological Sequelae of Torture and Incarceration. In: Schouler-Ocak M. (eds) Trauma and Migration (pp. 95-107). Springer, Cham. https://doi.org/10.1007/978-3-31917335-1_8

Hodges-Wu, J., \& Zajicek-Farber, M. (2017). Addressing the Needs of Survivors of Torture: A Pilot Test of the Psychosocial Well-Being Index. fournal of Immigrant $\mathcal{E}$ Refugee Studies, 15(1), 71-89. https://doi.org/10.1080/15562948.2016. 1171941

Hollander, A.-C., Dal, H., Lewis, G., Magnusson, C., Kirkbride, J. B., \& Dalman, C. (2016). Refugee migration and risk of schizophrenia and other non-affective psychoses: cohort study of 1.3 million people in Sweden. BMF, 352, i1030. https://doi.org/10.1136/bmj

Kira, I. A. (2010). Etiology and treatment of post-cumulative traumatic stress disorders in different cultures. Traumatology, 16(4), 128. https://doi. org/10.1177/1534765610365914

Kirmayer, L., \& Ramstead, M. J. (2017). Embodiment and Enactment in Cultural Psychiatry. In Durt, C., Fuchs, T. \& Tewes, C. (Eds.) Embodiment, enaction, and culture: Investigating the constitution of the shared world. Cambridge, MA: MIT Press. 2017, p. 397-422.

Kotsioni, I. (2016). Rehabilitation for survivors of torture and other forms of ill-treatment in Athens, Greece - Responding to a protracted refugee crisis. Paper presented at the 4th MSF Workshop on the thematic of torture: caring for the human beyond the torture, Rome, Italy.

MDM [Medecins Du Monde/Doctors of the World]. (2016). Legal report on access to healthcare in 17 countries. European Network to Reduce Vulnerabilities in Health.

Miller, K., \& Rasmussen, A. (2017). The mental health of civilians displaced by armed conflict: an ecological model of refugee distress. Epidemiology and psychiatric sciences, 26(2), 129-138. https://doi.org/10.1017/S2045796016000172

MSF, [Medecins Sans Frontieres/Doctors Without Borders] (2016). Obstacle Course to Europe: A policy-made humanitarian crisis at EU borders. https:// www.doctorswithoutborders.org/article/obstaclecourse-europe-policy-made-humanitarian-crisiseu-borders on 30/05/2018.

Navarro-Lashayas, M. A., Pérez-Sales, P., LopesNeyra, G., Martínez, M. A., \& Morentin, B. (2016). Incommunicado detention and torture in Spain, Part IV: Psychological and psychiatric consequences of ill-treatment and torture: trauma and human worldviews. Torture, 26(3), 34-45.

Papadopoulos, R. (2007). Refugees, trauma and adversity-activated development. European fournal of Psychotherapy and Counselling, 9(3), 301-312. https://doi.org/10.1080/13642530701496930

Patel, N., Kellezi, B., \& Williams, A. C. d. C. (2014). Psychological, social and welfare interventions for psychological health and well-being of torture survivors. The Cochrane Library. https://doi. org/10.1002/14651858.CD009317.pub2

Schock, K., Böttche, M., Rosner, R., Wenk-Ansohn, M., \& Knaevelsrud, C. (2016). Impact of new traumatic or stressful life events on pre-existing PTSD in traumatized refugees: results of a longitudinal study. Eur F Psychotraumatol., 2016, 7 (32106). https://doi: 10.3402/ejpt.v7.32106

Schock, K., Rosner, R., \& Knaevelsrud, C. (2015). Impact of asylum interviews on the mental health of traumatized asylum seekers. Eur F Psychotraumatol., 6. https://doi.org/10.3402/ejpt.v6.26286

Silove, D., Ventevogel, P., \& Rees, S. (2017). The con- 
temporary refugee crisis: an overview of mental health challenges. World Psychiatry, 16(2), 130-139. https://doi.org/10.1002/wps.20438

Sironi, F. (1999). Bourreaux et victimes: psychologie de la torture. [Executioners and victims: psychology of torture]. Odile Jacob.

Song, S. J., Kaplan, C., Tol, W. A., Subica, A., \& de Jong, J. (2015). Psychological distress in torture survivors: pre-and post-migration risk factors in a US sample. Social Psychiatry and Psychiatric Epidemiology, 50(4), 549-560. https://doi.org/10.1007/s00127-014-0982-1

Song, S. J., Subica, A., Kaplan, C., Tol, W., \& de Jong, J. (2017). Predicting the Mental Health and Functioning of Torture Survivors. The fournal of nervous and mental disease. 206 (1), 33-39. https://doi.org/10.1097/ NMD.0000000000000678

ter Heide, F. J. J., Mooren, T. M., \& Kleber, R. J. (2016). Complex PTSD and phased treatment in refugees: a debate piece. Eur $\mathcal{F}$ Psychotraumatol., 7.

UNHCR. (2017). Torture victims in the context of migration: identification, redress and rehabilitation.

Viñar, M. N. (2005). La spécificité de la torture comme source de trauma [The specificity of torture as a source of trauma]. Revue française de psychanalyse, 69(4), 1205-1224.

Whitsett, D., \& Sherman, M. F. (2017). Do resettlement variables predict psychiatric treatment outcomes in a sample of asylum-seeking survivors of torture? International fournal of Social Psychiatry, 63(8), 674-685. https://doi. org/10.1177/0020764017727022 